\title{
Macular degeneration: do conventional measurements of impaired visual function equate with visual disability?
}

\author{
M E McClure, P M Hart, A J Jackson, M R Stevenson, U Chakravarthy
}

\begin{abstract}
Aims-To examine the relation between measures of vision and ability to perform daily living tasks in those visually impaired with macular degeneration.

Methods-A visual functioning index (daily living tasks dependent on vision: DLTV) was used to evaluate patients' perception of their ability to perform vision dependent tasks. Distance visual acuity, near visual acuity, reading speed, and contrast sensitivity were measured in all patients. In addition, a new measure of reading ability was derived, designated the reading index. This takes into account both the size of the text read and the time to read it and is equivalent to the reading speed in words per minute divided by text size in $M$.
\end{abstract}

Results-The reading index was found to show best associations with the majority of items within the DLTV. Stepwise regression identified the combination of reading index and distance visual acuity as having the best associations with DLTV items. The present study also demonstrated that specific levels of vision as measured by acuity, reading index, and contrast sensitivity corresponded with different perceived amounts of difficulty in the performance of daily living tasks. Conclusions-This study showed that reading index is valuable in predicting the ability to perform daily living tasks and therefore may be useful in the visual assessment of the visually impaired individual. In addition, this study identified specific levels of vision at which individuals reported different degrees of difficulty in performing daily living tasks.

(Br f Ophthalmol 2000;84:244-250)

It is standard clinical practice to measure visual function in terms of distance and near visual acuity. Such measures determine resolution, which is the ability of the visual system to detect spatial changes at high contrast. Additional means of assessing vision such as contrast sensitivity, which is resolution at variable contrast, and reading speed, which measures fluency, are usually confined to areas of research. Historically, it has been assumed that these quantifiable measurements of distance and near visual acuity equate to one's ability to function in the seeing world. However, it is now widely recognised that these variables may not provide a true representation of the ability to perform vision dependent daily living tasks, particularly in those individuals who have visual impairment. ${ }^{1}$ A number of reasons have been suggested to explain why this may be so. These include the fact that acuity is a measure of the ability to resolve letters displayed at maximum contrast and extending only over the central 1-2 degrees of visual field.

In addition to resolution, the ability to read small print for any length of time is dependent on many other components of the visual system including eye movements and visual processing. Thus, acuity is not the only determining factor when an individual reads a paragraph of text.

Previous studies have shown that additional variables such as contrast sensitivity also play an important part in vision. ${ }^{2}$ The amount of contrast needed for a grating or edge to be just detectable is the contrast threshold and its reciprocal is contrast sensitivity. Reading material rarely consists of high contrast black characters on a perfectly white background providing $100 \%$ contrast level. The text contrast level of newspaper print, for example, is between $60 \%$ and $70 \%$. Paperback books and laser print paper have a text contrast level of $75 \%$ and $94 \%$ respectively. ${ }^{3}$ Objects in the real world are generally of different degrees of contrast.

Thus, it is becoming increasingly clear that vision is a highly complex function, comprising among other variables, distance and near visual threshold, contrast ability, visual fields, colour sensitivity, and light and dark adaptation. In disease, each of these may be affected to a different extent. ${ }^{4}$

Quality of life (QoL) instruments and visual functioning indices (VFI) provide a measure of patients' own perception of their disability, and have recently gained popularity for estimating visual function. ${ }^{56} \mathrm{~A}$ VFI consists of a collection of carefully constructed questions aimed at assessing an individual's ability to perform vision dependent tasks. Several studies have used VFI and QoL to assess outcome, most notably in the evaluation of the impact of cataract surgery. ${ }^{7-10}$ Other visual disorders where VFI were found to be useful include the management of cytomegalovirus retinitis, ${ }^{11}$ glaucoma, ${ }^{12}$ and blepharoptosis. ${ }^{13}$

In macular degeneration subjects can suffer a profound irreversible central visual loss in one or both eyes. ${ }^{14}$ Until recently, no VFI had been constructed and validated to assess the visual ability of people with age related macular degeneration (AMD) who are usually in their
Accepted for publication 1 October 1999 
sixth decade of life or older. In 1995 we constructed and validated a VFI, "the daily living tasks dependent on vision (DLTV)", for use in older subjects which was piloted in three groups; those with no history of visual problems, cataract sufferers, and AMD sufferers. ${ }^{15}$ This study showed that the DLTV correlated well with distance visual acuity in the better eye and was able to discriminate between the three groups of subjects. ${ }^{15}$ This study did not attempt to correlate other factors of vision, such as near acuity, reading speed, and contrast sensitivity which are also aspects of visual function with the DLTV. The present study was designed to identify which conventional measures of vision correlate best with patients' perception of their visual disability in AMD and the level at which difficulty was perceived.

\section{Methods \\ SUBJECTS \\ One hundred individuals who were attending an ophthalmic outpatient research clinic at the Royal Victoria Hospital, Belfast, were recruited to this study during the period February 1996 to December 1997. None of the participants was involved in any other study protocols and they ranged in age from 47 to 97 years with a mean of 74 (SD 8) years; 33 subjects were male and 67 were female. All subjects attending the clinic had previously diagnosed macular de- generation. Informed consent was obtained from all subjects before testing.}

VISUAL FUNCTION ASSESSMENT

Each subject had distance and near visual acuity, reading speed, and contrast sensitivity measured on each eye under standardised illumination.

DISTANCE VISUAL ACUITY

The optimal distance correction was obtained using a standardised refraction protocol. Acuity was measured using Bailey-Lovie charts according to the Macular Photocoagulation Study (MPS) manual of procedures. ${ }^{16}$

NEAR VISUAL ACUITY

Near acuities were recorded through a +4.00 reading addition worn over the optimal distance correction. Near vision was measured for each eye using the Bailey-Lovie near visual acuity test types at $25 \mathrm{~cm} .{ }^{17}{ }^{18}$ These charts consist of a collection of randomly selected words, gradually decreasing in size from $10 \mathrm{M}$ (N80) to $0.25 \mathrm{M}(\mathrm{N} 2)$ in logarithmic progression from line to line. ${ }^{18}$

READING SPEED

The near reading charts which we constructed and used for evaluation of reading speed were designed using words of the same range and mix as the Bailey-Lovie near acuity chart which has been previously validated. ${ }^{18}$ Charts with different print size ranging from $1.0 \mathrm{M}$ to $10 \mathrm{M}$ and containing between 60 and 12 words were constructed. The number of words on each line ranged from 2 to 26 , the words were unconnected and consisted of 4,7 , or 10 letters. Combinations of words were similar across the range of print sizes. The number of correctly read words was recorded at the end of testing. Those words incorrectly read, reread, or missed were recorded as incorrect reading words.

At testing the subject was provided with a chart exhibiting text two logarithmic steps larger than their near acuity threshold. Print sizes smaller than $1.0 \mathrm{M}$ were not used, even if the subject's near acuity was more than two steps better than this. Where near acuity was $8.0 \mathrm{M}$ or greater, it is impractical to provide appropriately sized text $(12 \mathrm{M})$ and reading speed could therefore not be measured in these patients. For the purpose of statistical analysis, the reading speed was approximated to zero in such patients in this study. The subject was asked to read the print steadily. Reading steadily is reading without stopping or interruption at a comfortable pace. Subjects were advised that they were being timed but asked to read without rushing. The subject was instructed to commence reading and the timer was activated. The timer was stopped when the subject had finished the paragraph or after 1 minute whichever was sooner.

\section{READING INDEX}

Reading index is defined as the reading speed (words per minute) as a function of the print size measured in $M$. For example a subject reading 60 words in 1 minute at $2.0 \mathrm{M}$ has a reading index of 30 reading index units.

\section{CONTRAST SENSITIVITY}

Contrast sensitivity was measured using the Pelli-Robson chart. ${ }^{19}{ }^{20}$ As recommended, the patient was seated at a distance of 1 metre from the chart which was positioned at eye level. A correction of +0.75 DS was added to that used for distance acuity testing.

\section{VISUAL FUNCTIONING INDEX}

The DLTV which has been described in a previous publication was the questionnaire used in this study. ${ }^{15}$ It consists of 22 items (Table 1) covering tasks dependent on distance and near acuity, depth and contrast perception, light and dark adaptation, and visual fields. Each item is graded into four responses, from "no difficulty" to "vision prevents". Where an individual did not do the task for non-visual reasons, this item was left blank. Using an average of responses to all other items, the response to the ungraded item was then scored on the spreadsheet. The instrument was administered by a single experienced interviewer in every case.

STATISTICAL ANALYSES: CORRELATIONS AND ASSOCIATIONS

The data were entered into a database and analysed using sPSS. The correlations between each recorded measure of vision (distance and near acuity, reading speed, reading index, and contrast sensitivity) in the better and worse eyes, of each individual's pair of eyes, were examined using Pearson's product moment correlation coefficient. 
Table 1 Items within the daily living tasks dependent on vision (DLTV) questionnaire

\begin{tabular}{|c|c|c|c|c|c|}
\hline \multicolumn{2}{|c|}{ How much difficulty do you have } & \multirow{2}{*}{$\begin{array}{l}\text { No difficulty } \\
4\end{array}$} & \multirow{2}{*}{$\begin{array}{l}\text { A little } \\
\text { difficulty }\end{array}$} & \multirow{2}{*}{$\begin{array}{l}\text { A lot of } \\
\text { difficulty }\end{array}$} & \multirow{2}{*}{$\begin{array}{l}\text { Cannot see } \\
\text { to do }\end{array}$} \\
\hline 1 & Distinguishing a person's features across the room & & & & \\
\hline 2 & Noticing objects off to either side & 4 & 3 & 2 & 1 \\
\hline 3 & Watching television programmes & 4 & 3 & 2 & 1 \\
\hline 4 & Seeing steps and using them & 4 & 3 & 2 & 1 \\
\hline 5 & Enjoying the scenery if out for a drive & 4 & 3 & 2 & 1 \\
\hline 6 & Reading road signs/street names & 4 & 3 & 2 & 1 \\
\hline 7 & Distinguishing a person's features across the street & 4 & 3 & 2 & 1 \\
\hline 8 & Recognising seasonal changes in the garden & 4 & 3 & 2 & 1 \\
\hline 9 & Distinguishing a person's features at arm's length & 4 & 3 & 2 & 1 \\
\hline 10 & Pouring yourself a drink & 4 & 3 & 2 & 1 \\
\hline 11 & Cutting up food on your plate & 4 & 3 & 2 & 1 \\
\hline 12 & Cutting your finger nails & 4 & 3 & 2 & 1 \\
\hline 13 & Using kitchen appliances & 4 & 3 & 2 & 1 \\
\hline 14 & Adjusting to darkness after being in the light & 4 & 3 & 2 & 1 \\
\hline 15 & Adjusting to the light after being in the dark & 4 & 3 & 2 & 1 \\
\hline \multicolumn{6}{|c|}{ How confident do you feel in your ability to walk around } \\
\hline & & Extremely & Somewhat & Barely & Not at all \\
\hline 16 & In your immediate neighbourhood & 4 & 3 & 2 & 1 \\
\hline 17 & Outside your immediate neighbourhood & 4 & 3 & 2 & 1 \\
\hline \multicolumn{6}{|c|}{ With your near glasses on how much difficulty do you have } \\
\hline & & No difficulty & $\begin{array}{l}\text { A little } \\
\text { difficulty }\end{array}$ & $\begin{array}{l}\text { A lot of } \\
\text { difficulty }\end{array}$ & $\begin{array}{l}\text { Cannot see } \\
\text { to do }\end{array}$ \\
\hline 18 & Reading normal sized newspaper print & 4 & 3 & 2 & 1 \\
\hline 19 & Reading newspaper headlines & 4 & 3 & 2 & 1 \\
\hline 20 & Reading correspondence - eg, bills, letters, cards & 4 & 3 & 2 & 1 \\
\hline 21 & Signing documents (cheques, pension book) & 4 & 3 & 2 & 1 \\
\hline 22 & Identifying money from purse or wallet & 4 & 3 & 2 & 1 \\
\hline
\end{tabular}

The correlations between single measures of vision and individual DLTV scores were also examined by Pearson's correlation coefficients.

The relations between combinations of measures of vision (explanatory variables) and individual DLTV scores were examined by regression analysis, with DLTV items as dependent variables. Care was exercised when selecting potential combinations of explanatory variables to minimise multicolinearity between these variables. All explanatory variables (measures of vision) in the better and worse eye were entered into a hierarchical cluster. The first measure of vision which was the most graphically separable variable was the first to be selected for the final regression model. This variable was then correlated with the remaining variables to find the one which was least correlated with it. This was then the second variable to be entered into the regression model. The combination of these two variables was then used as a single independent variable and regressed against each of the measures of vision. The variable showing least association was then chosen to be entered into the final regression model. This third variable was then combined with the first two and the combination used again as the independent variable which was regressed against the remaining measures of vision to determine the one with least association. This was continued until six variables had been selected for the final regression model.

Table 2 Measures of vision in better and worse eyes

\begin{tabular}{lllllll}
\hline & \multicolumn{3}{l}{ Better eye } & & & \multicolumn{2}{l}{ Worse eye } \\
\cline { 2 - 3 } \cline { 5 - 6 } Measures of vision & Mean $(S D)$ & Range & & & Mean $(S D)$ & Range \\
\hline Distance visual acuity (logMAR) & $0.5(0.5)$ & $-0.2-1.6$ & & $1.2(1.2)$ & $0.1-1.6$ \\
Near visual acuity (M) & $2.5(3)$ & $0.5-10$ & & $6.3(4.6)$ & $0.5-10$ \\
Reading index wpm/print size (M) & $39(35)$ & $133-0$ & & $9(16)$ & $71-0$ \\
Contrast sensitivity (log units) & $1.20(0.4)$ & $1.80-0$ & & $0.60(0.5)$ & $1.50-0$ \\
\hline
\end{tabular}

Only relations where the adjusted coefficient of determination (adjusted $R^{2}$ ) was greater than 0.25 are shown.

\section{LEVELS OF VISION ASSOCIATED WITH DLTV} SCORES

This is the anticipated value of each measure of vision that equates to a given DLTV score. This was derived from a regression model. Each item on the DLTV is given a score from 1 to 4 according to the subject's response: "no difficulty" (4), "a little of difficulty" (3), "a lot of difficulty" (2), "vision prevents" (1) (see Table 6). It would be expected that those with impaired visual function would show lower scores. Using regression analysis we determined, for each measure of vision, that value of vision corresponding to a given score on the DLTV. The dependent variables were the measures of vision and the explanatory variable was the total DLTV score for the 22 items.

The regression equation, $y=a+b_{1} x_{1}$, was used to calculate levels of vision as shown in Table 6 , where $\mathrm{y}=$ the value of vision to be determined, $a=$ constant, $b=$ regression coefficient, $\mathrm{x}=$ DLTV score.

To determine the level of distance visual acuity when an individual scores 1 on every item in the DLTV, the equation can be written as follows:

$\mathrm{y}=1.687+\left(-1.9 \times 10^{-2} \times 22\right)=1.3 \log \mathrm{MAR}$

The same equation was used to calculate values of vision as shown in Table 6 .

\section{Results}

VISUAL ACUITY, READING INDEX, AND CONTRAST SENSITIVITY MEASURES

The 100 subjects tested showed a wide range of acuity, reading index, and contrast sensitivity measurements in the better and worse eyes. The mean, minimum, and maximum value for each measure of vision in better and worse eyes 

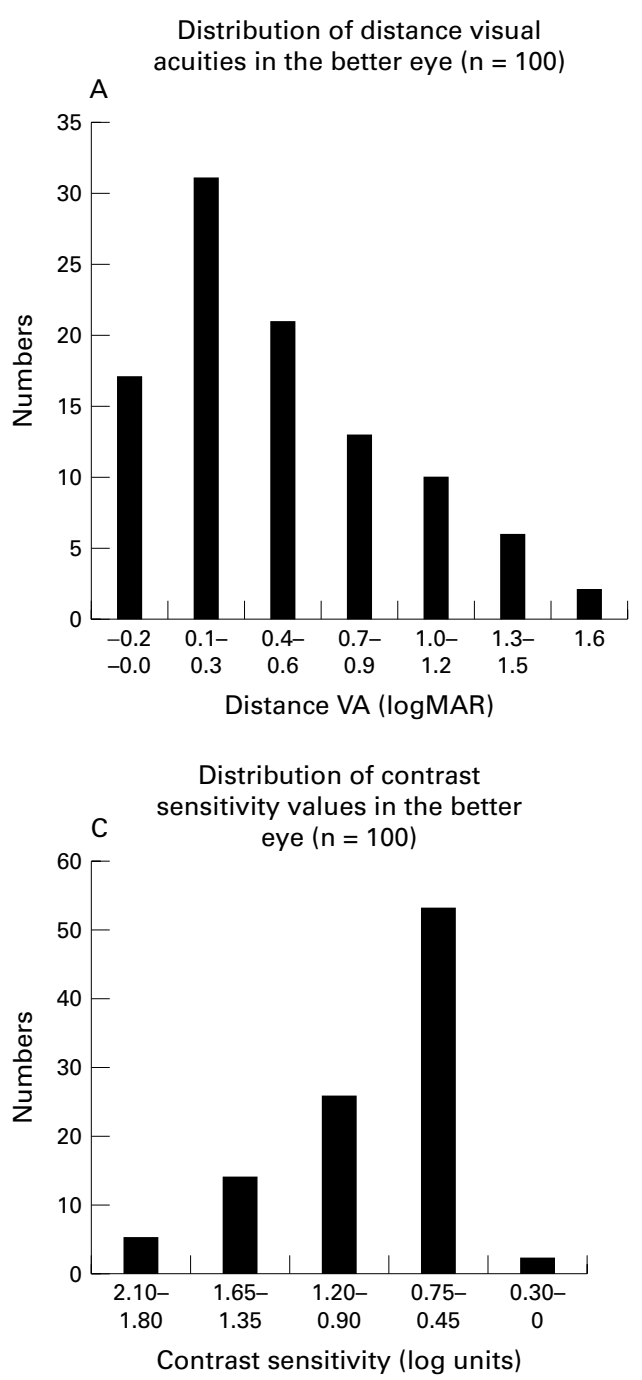

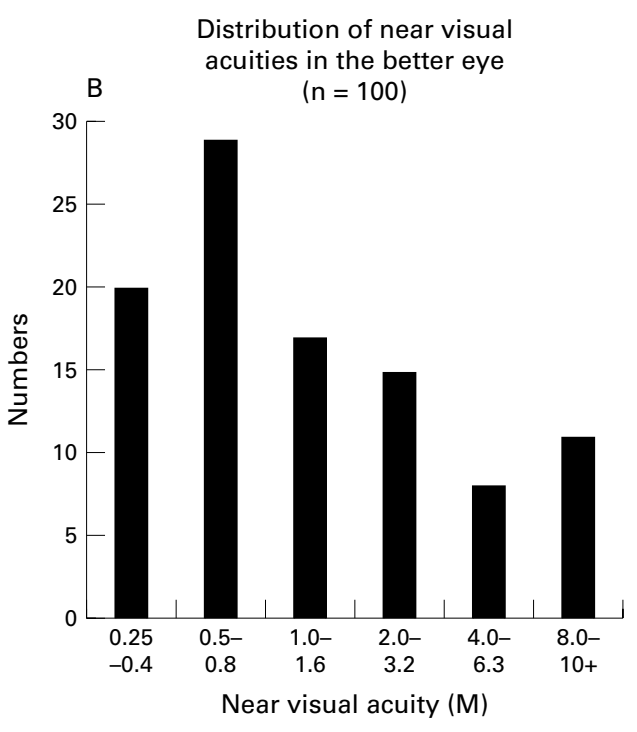

Distribution of reading index

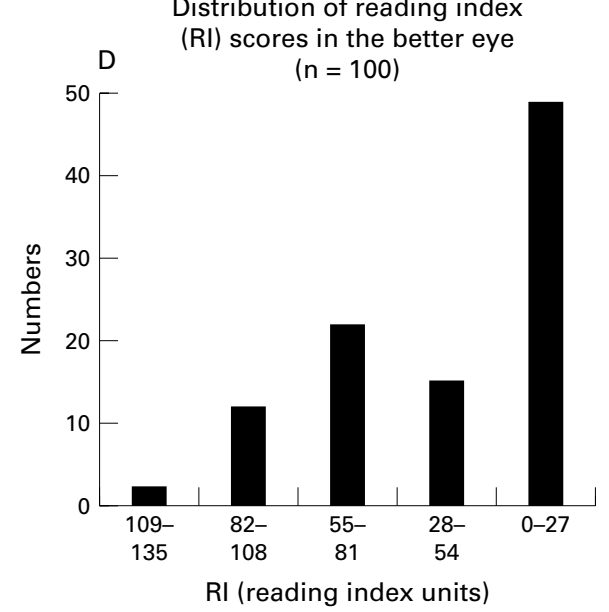

Figure 1 Distribution of various factors in individuals tested in the better eye.

are summarised in Table 2. Figure 1 shows that the individuals tested exhibited a range of vision from excellent to severely impaired in the better eye.

\section{CORRELATIONS BETWEEN DIFFERENT MEASURES} OF VISION

High degrees of correlation were found between all measures of vision using Pearson's product moment (Table 3). In the better eye group, distance visual acuity was significantly correlated with near visual acuity. Contrast sensitivity showed correlation with distance visual acuity, near visual acuity, and reading index.

Table 3 Pearson's product moment correlation coefficients between measures of vision in better and worse eyes

\begin{tabular}{|c|c|c|c|}
\hline & $\begin{array}{l}\text { Distance } \\
\text { visual acuity }\end{array}$ & $\begin{array}{l}\text { Near visual } \\
\text { acuity }\end{array}$ & $\begin{array}{l}\text { Reading } \\
\text { index }\end{array}$ \\
\hline \multicolumn{4}{|l|}{ Better eye } \\
\hline Near visual acuity & 0.79 & & \\
\hline Reading index & 0.73 & 0.62 & \\
\hline Contrast sensitivity & 0.76 & 0.72 & 0.67 \\
\hline \multicolumn{4}{|l|}{ Worse eye } \\
\hline Near visual acuity & 0.53 & & \\
\hline Reading index & 0.36 & 0.32 & \\
\hline Contrast sensitivity & 0.50 & 0.59 & 0.59 \\
\hline
\end{tabular}

When compared with correlations in the better eye group, the correlations in the worse eye group were lower, particularly between reading index and each of distance and near acuity.

\section{RESPONSES TO THE DLTV QUESTIONNAIRE}

The DLTV took no longer than 15 minutes to administer to an individual. No subjects reported any difficulty responding to the items in the DLTV. By assessing responses to the questionnaire, in total, $17 \%$ of individuals had the same scores in $86.4 \%$ or more of the items.

MEASURES OF VISION AND DLTV ITEMS

Pearson's product moment correlation coefficients confirmed that the ability to perform daily living tasks was more strongly correlated with measures of vision recorded in the better eye than in the worse eye. The associations between each measure of vision in the better eye and DLTV items are shown in Table 4. Reading index in the better eye was found to exhibit stronger correlations with five of the DLTV items when compared with other measures of vision. Distance visual acuity too showed best correlations with the same tasks. 
Table 4 Pearson's correlation coefficients between individual DLTV items and individual measures of vision in the better and worse eye

\begin{tabular}{|c|c|c|c|c|c|}
\hline & $\begin{array}{l}\text { Distance } \\
\text { visual acuity }\end{array}$ & $\begin{array}{l}\text { Near visual } \\
\text { acuity }\end{array}$ & Reading index & Reading speed & $\begin{array}{l}\text { Contrast } \\
\text { sensitivity }\end{array}$ \\
\hline Read correspondence & $0.70(0.22)$ & $0.58(0.43)$ & $0.77(0.46)$ & $0.69(0.46)$ & $0.61(0.43)$ \\
\hline Read newspaper print & $0.69(0.25)$ & $0.51(0.39)$ & $0.76(0.44)$ & $0.67(0.43)$ & $0.56(0.36)$ \\
\hline Sign documents & $0.67(0.23)$ & $0.58(0.41)$ & $0.76(0.42)$ & $0.69(0.45)$ & $0.61(0.44)$ \\
\hline Detect facial features across a room & $0.61(0.24)$ & $0.50(0.35)$ & $0.66(0.37)$ & $0.57(0.36)$ & $0.57(0.37)$ \\
\hline Distinguish cash & $0.60(0.10)$ & $0.52(0.34)$ & $0.65(0.36)$ & $0.58(0.36)$ & $0.55(0.41)$ \\
\hline Read newspaper headlines & $0.64(0.23)$ & $0.60(0.40)$ & $0.64(0.35)$ & $0.59(0.38)$ & $0.56(0.41)$ \\
\hline Read street signs & $0.62(0.08)$ & $0.49(0.28)$ & $0.61(0.28)$ & $0.55(0.27)$ & $0.49(0.29)$ \\
\hline Detect facial features across a road & $0.57(0.29)$ & $0.47(0.38)$ & $0.58(0.36)$ & $0.53(0.34)$ & $0.55(0.41)$ \\
\hline Detect facial features at arm's length & $0.56(0.08)$ & $0.47(0.28)$ & $0.59(0.32)$ & $0.56(0.31)$ & $0.51(0.25)$ \\
\hline Detect seasonal changes & $0.53(0.10)$ & $0.49(0.10)$ & $0.50(0.28)$ & $0.44(0.27)$ & $0.46(0.32)$ \\
\hline Use kitchen utensils & $0.57(0.12)$ & $0.52(0.37)$ & $0.62(0.35)$ & $0.56(0.36)$ & $0.58(0.41)$ \\
\hline Watch television & $0.54(0.17)$ & $0.55(0.35)$ & $0.56(0.24)$ & $0.55(0.32)$ & $0.55(0.35)$ \\
\hline Pour a drink & $0.48(0.11)$ & $0.50(0.40)$ & $0.51(0.31)$ & $0.47(0.37)$ & $0.52(0.47)$ \\
\hline Confidence to walk around in a strange area & $0.56(0.23)$ & $0.46(0.38)$ & $0.53(0.35)$ & $0.47(0.31)$ & $0.55(0.47)$ \\
\hline Ability to appreciate scenery & $0.53(0.04)$ & $0.42(0.18)$ & $0.40(0.23)$ & $0.37(0.21)$ & $0.30(0.20)$ \\
\hline Confidence to walk around in own area & $0.54(0.19)$ & $0.51(0.30)$ & $0.48(0.25)$ & $0.42(0.24)$ & $0.45(0.35)$ \\
\hline Cut finger nails & $0.50(0.14)$ & $0.52(0.45)$ & $0.58(0.39)$ & $0.57(0.45)$ & $0.46(0.39)$ \\
\hline
\end{tabular}

*Correlations for the worse eye are represented in parentheses.

These included reading correspondence and newsprint, ability to sign documents, detect facial features across a room, and identify cash. Near acuity alone and contrast sensitivity alone did not show any better correlations with the items in this questionnaire than other measures of vision.

COMBINATIONS OF MEASURES OF VISION AND DLTV ITEMS

Using step wise regression, combinations of measures of vision were identified which showed strong relations with the ability to perform daily living tasks (Table 5). The combination of reading index and distance visual acuity showed the strongest association with 10 of the 22 DLTV items. Three items within the DLTV were best associated with the combination of reading index and contrast sensitivity. The combination of distance visual acuity and con-

Table 5 Associations between combinations of measures of vision in the better eye and DLTV items

\begin{tabular}{|c|c|c|c|}
\hline Daily living task & Measures of vision & $\begin{array}{l}\text { Adjusted } \\
R^{2}\end{array}$ & $\begin{array}{l}\text { Significance for } \\
\text { coefficient of } \\
\text { determination }\end{array}$ \\
\hline Read correspondence & $\begin{array}{l}\text { Reading index and } \\
\text { distance visual acuity }\end{array}$ & 0.63 & 0.000 \\
\hline Read newspaper print & & 0.61 & 0.000 \\
\hline Sign documents & & 0.60 & 0.000 \\
\hline Detect facial features across a room & & 0.46 & 0.000 \\
\hline Distinguish cash & & 0.44 & 0.000 \\
\hline Read newspaper headlines & & 0.46 & 0.000 \\
\hline Read street signs & & 0.42 & 0.000 \\
\hline Detect facial features across a road & & 0.37 & 0.000 \\
\hline Detect facial features at arm's length & & 0.37 & 0.000 \\
\hline Detect seasonal changes & 0.30 & 0.000 & \\
\hline Use kitchen utensils & $\begin{array}{l}\text { Reading index and } \\
\text { contrast sensitivity }\end{array}$ & 0.42 & 0.000 \\
\hline Watch television & & 0.35 & 0.000 \\
\hline Pour a drink & 0.31 & 0.000 & \\
\hline Confidence to walk in a strange area & $\begin{array}{l}\text { Distance visual acuity } \\
\text { and contrast sensitivity }\end{array}$ & 0.33 & 0.008 \\
\hline Ability to appreciate scenery & 0.30 & 0.000 & \\
\hline
\end{tabular}

Table 6 Values of each measure of vision associated with DLTV scores

\begin{tabular}{|c|c|c|c|c|}
\hline & $\begin{array}{l}\text { DLTV } \\
\text { score: } 4: \\
\text { No difficulty }\end{array}$ & $\begin{array}{l}\text { DLTV } \\
\text { score: } 3: \\
\text { A little } \\
\text { difficulty }\end{array}$ & $\begin{array}{l}\text { DLTV } \\
\text { score: } 2: \\
\text { A lot of } \\
\text { difficulty }\end{array}$ & $\begin{array}{l}\text { DLTV } \\
\text { score: } 1 \text { : } \\
\text { Vision prevents }\end{array}$ \\
\hline $\begin{array}{l}\text { Distance visual acuity: } \log \text { MAR } \\
\text { (Snellen) }\end{array}$ & $0.0(6 / 6)$ & $0.4(6 / 15)$ & $0.9(6 / 48)$ & $1.3(6 / 120)$ \\
\hline Near visual acuity: $M(N)$ & $0.32 \mathrm{M}(\mathrm{N} 2.5)$ & $1.0 \mathrm{M}(\mathrm{N} 8)$ & $3.2 \mathrm{M}(\mathrm{N} 24)$ & $10.0 \mathrm{M}(\mathrm{N} 80)$ \\
\hline Reading index: wpm/ print size & 73 & 32 & 8 & 0 \\
\hline Contrast sensitivity: $\log$ units & 1.50 & 1.20 & 0.90 & 0.60 \\
\hline
\end{tabular}

trast sensitivity were associated with two items on the DLTV.

ANTICIPATED VALUE FOR EACH MEASURE OF VISION AS PREDICTED BY THE DLTV SCORE

Subjects with a visual acuity of $0.0 \log$ MAR generally reported no difficulty performing tasks. Subjects with an acuity of $0.4 \log$ MAR reported "a little difficulty" while those with an acuity of $0.9 \log$ MAR reported "a lot of difficulty" in the performance of tasks. When the value of acuity was $1.3 \log$ MAR, the most severe level of difficulty was reported. The separation of the four categories, each corresponding to one step on the DLTV scale, corresponded to a distance acuity difference of approximately four logMAR lines. A difference of three lines on the $\log M A R$ chart represents a doubling of the visual angle.

Subjects with a near visual acuity of $0.32 \mathrm{M}$ (N2.5) generally reported "no difficulty", 1.0 M (N8) "a little difficulty", 3.2M (N24) "a lot of difficulty" to perform a task. Those reporting "a lot of difficulty" in the performance of a task had a near visual acuity of $10 \mathrm{M}$ (N80).

A subject with a reading index of 73 could be expected to report "no difficulty" in reading. Only subjects who were able to perceive print sizes smaller than 1.0M achieved this. Similarly a further reduction in the reading index was associated with varying levels of difficulty (Table 6).

When subjects were grouped according to contrast sensitivity, a decrease of $0.3 \log$ units was accompanied by an increase of one step in the difficulty score on the DLTV instrument (Table 6).

\section{Discussion}

The aim of the present study was to examine the associations between self reported visual functioning, as assessed by the DLTV instrument, and four measures of vision-namely, distance and near acuity, reading index, and contrast sensitivity.

We examined the correlations between measures of vision, grouping eyes by visual status - that is, the better or worse eye of an individual's pair of eyes. In better eyes, high 
correlations were seen between all measures of vision while in worse eyes lower correlations were observed. This may be because individuals are unpractised at visual tasks with their worse eye.

The results of the present study demonstrated that all measures of vision in the better eye had a strong association with the ability to perform daily living tasks. Reading index, a novel derivative of reading speed, consistently showed the highest correlations with the majority of DLTV items. Reading speed has been used extensively in psychophysical studies of central visual function and has been shown to be useful in the evaluation of disability in diseases such as macular degeneration. ${ }^{21}$ As reading speed is simply the number of words read per minute, it does not allow differentiation of subjects who can read small print sizes at a given speed from those who can only read larger sizes at the same speed. Thus, it can be surmised that size of print, together with resolving power of the eye and speed of reading are important factors.

It was noteworthy that distance visual acuity was better associated with more DLTV tasks than near visual acuity. Letter measurement of distance acuity is a precise standardised test in which the patient's threshold to resolve the size of the letter is clearly defined. By comparison, word identification as a measure of near visual acuity may be prone to subjective estimation where only some letters are seen and the whole word is guessed. Other factors such as IQ, social status, and years in education may also influence reading ability. This fundamental difference between the methods of recording distance and near acuity may explain why the former showed better association with DLTV tasks than near acuity.

Strong associations with DLTV items were detected when combinations of measures of vision were used in the regression analysis. It was noteworthy that the combination of distance visual acuity and reading index was found to show strongest association with many items of the DLTV, thus emphasising the importance of resolution in the performance of these tasks.

Some items concerning tasks such as using kitchen utensils, cutting up food on a plate and watching television, showed modest associations with the combination of contrast sensitivity and reading index. These findings suggest that while these tasks are obviously contrast dependent they are also related to resolution of the eye and sustained use of near vision. The combination of distance visual acuity and contrast sensitivity was also found to have modest associations with a number of DLTV items. These findings are in accordance with those of other studies which have shown contrast sensitivity to be an important factor in visual function. ${ }^{22-24}$

Certain questions in the DLTV were not significantly correlated with any of the tests carried out in this study. No one test or combination of tests predicted ability to adjust to dark after being in the light or vice versa. This was not surprising as the more appropriate tests to predict the ability to dark adapt were not carried out and is a reflection of the construct validity of the instrument.

When the association between each measure of vision and the level of difficulty experienced by the subject in performing daily living tasks was examined, a relation became evident. When the acuity in the better eye was 0.0 logMAR patients were likely to have no difficulty on any given task (score $=4)$. As distance visual acuity changed by approximately 0.4 $\log$ MAR the amount of difficulty perceived by the subjects altered from "none" to "a little" to "a lot" to "vision prevents". Similar relations were found between the self reported level of difficulty and other measures of vision such as with near visual acuity, reading index, and contrast sensitivity. In particular, it was noteworthy that a decline in contrast sensitivity to 1.20 $\log$ units was noticeable to the subjects in the present study as causing a little difficulty in the performance of tasks. Such an association has been suggested previously. ${ }^{19}$

The present study determined the values of reading index which corresponded to the perceived levels of difficulty on the DLTV scale. A reading index of 73 corresponded to "no difficulty", 32 to "a little difficulty", 8 to "a lot of difficulty", and 0 to "vision prevents". It has been suggested by Whittaker and LovieKitchin that an individual needs a reading rate of 160 words per minute for high fluent reading, 80 words per minute for fluent reading, and 40 words per minute to manage spot reading. ${ }^{24}$ Thus, the findings of the present study are in accordance with the value found for "fluent reading" by Whittaker and Lovie-Kitchin. In addition, the findings of the present study provide a better understanding of the disability experienced by visually impaired individuals.

The visual functioning index used in the present study has four levels of difficulty. Other instruments have used different scales. ${ }^{25}$ Thus, the application of these findings to other instruments will obviously require further study and we are currently undertaking this.

IMPLICATIONS FOR CLINICAL VISUAL FUNCTION TESTING

In an outpatient setting there are obvious restrictions in terms of time and expenditure when attempting to fully assess an individual's ability to perform tasks dependent on vision. Thus, it would be helpful to identify those tests that are most relevant to visual function. The results of the present study have shown that no single measure of vision is sufficient to explain all the variability in the performance of daily living tasks. The important aspects of vision relating to visual disability appear to be resolution at high contrast, speed of reading, and to a lesser extent contrast sensitivity. The present study highlighted the combination of reading index (a novel measure of reading speed) and distance visual acuity (a commonly used test of vision) as the measure of vision which correlated best with most DLTV items. Reading index measurements are performance based, readily standardised, easily used in 
clinical practice, and based on a principle familiar to the elderly patient. By measuring reading index the clinician may be able to predict both the patient's ability to perform tasks and the benefit of optical and non-optical aids. In the absence of facilities and time to carry out measurements of reading index, the present study has shown that distance visual acuity is still useful as an indication of ability to perform a range of vision dependent daily living tasks.

This study was supported by a strategic project grant awarded by the Medical Research Council.

The authors are grateful to Pat McEvoy for her help with the questionnaires in the study.

1 Ross C, Stelmack JA, Stelmack TR, et al. Preliminary examination of the reliability and relationship to clinical state of a measure of low vision patient functional status. Optom Vis Sci 1990;68:918-23.

2 Alexander MF, Maguire MG, Lietman TM, et al. Assessment of visual function in patients with age-related macular degeneration and low visual acuity. Arch Ophthalmol 1988;106:1543-7.

3 Cohen JM. Contrast of common near point reading materials. I Vis Rehab 1993;7:2-4.

4 Swann PG, Lovie-Kitchen JE. Age-related maculopathy. I: A review of its morphology and effects on visual function. Ophthalmic Physiol Opt 1990;10:149-56.

5 Scott IU, Schein OD, West S, et al. Functional status and quality of life measurement among ophthalmic patients. Arch Ophthalmol 1994;112:329-35.

6 Ellwein LB, Fletcher A, Negrel AD, et al. Quality of life assessment in blindness prevention interventions. Int $O p h-$ thalmol 1995;18:263-8.

7 Lundstrom M, Fregell G, Sjoblom A. Vision related daily life problems in patients waiting for a cataract extraction. Br f Ophthalmol 1994;78:608-1

8 Mangione CM, Philips RS, Lawrence et al. Improved visual function and attenuation of declines in health-related quality of life after cataract extraction. Arch Ophthalmol 1994;112:1419-25.
9 Elliott DB, Hurst MA, Weatherill J. Comparing clinical tests of visual function in cataract with the patient's perceived visual disability. Eye 1990;4:712-17.

10 Desai P, Reidy A, Minassian DC, et al. Gains form cataract surgery: visual function and quality of life. Brf Ophthalmol 1996;80:868-73.

11 Wu AW, Coleson LC, Holbrook J, et al. Measuring visual functioning and quality of life in patients with cytomegalovirus retinitis. Arch Ophthalmol 1996;114:841-7.

12 Parrish RK. Visual impairment, visual functioning and quality of life in patients with glaucoma. Trans Am Ophthalmol Soc 1996;94:919-1028.

13 Battu VK, Meyer DR, Wobig JL. Improvement in subjective visual function and quality of life measures after blepharoptosis. Am f Ophthalmol 1996;121:677-86.

14 Klein R, Wang Q, Klein BE, et al. The relationship of age-related maculopathy, cataract, and glaucoma to visual acuity. Invest Ophthalmol Visual Sci 1995;36:182-90.

15 Hart PM. Validity of a quality of life instrument. Invest $O p h-$ thalmol Vis Sci 1997;38:S676.

16 Macular Photocoagulation Study Group. Manual of procedures. Springfield, VA: National Technical Information Service, Accession No PB87-221834, April 1987.

17 Johnston AW. Making sense of the M, N and logMAR systems of specifying visual acuity. Probl Optom 1991;3: 394-407.

18 Bailey IL, Lovie JE The design and use of a new near-vision chart. Am f Optom Physiol Opt 1980;57:378-87.

19 Whittaker SG, Lovie-Kitchen JE. The assessment of contrast sensitivity and contrast reserve for reading rehabilitation. In: Kooijman AC, et al, eds. Low vision. Amsterdam: IOS Press, 1994:88-92.

20 Rumney NJ. Using visual thresholds to establish low vision performance. Ophthalmic Physiol Opt 1995;15:S18-24.

21 Ahn SJ, Legge GE, Luebker A. Printed cards for measuring low-vision reading speed. Vis Res 1995;35:1939-44

22 Kleiner RC, Enger C, Alexander MF, et al. Contrast sensitivity in age-related macular degeneration. Arch Ophthalmol 1988;106:55-7.

23 Leat SJ, Woodhouse JM. Reading performance with low vision aids: relationship with contrast sensitivity. Ophthalmic Physiol Opt 1993;13:9-15.

24 Whittaker SG, Lovie-Kitchin J. Visual requirements for reading. Optom Vis Sci 1993;70:54-65.

25 Mangione CM, Berry S, Spritzer K, et al. Identifying the content area for the 51 item NEIVFQ. Arch Ophthalmol 1998;116:227-33. 